\title{
Fatal pulmonary hypertension and rheumatoid vasculitis
}

\author{
V.P. Balagopal*, P. da Costa**, M.A. Greenstone*
}

Fatal pulmonary hypertension and rheumatoid vasculitis. V.P. Balagopal, P. da Costa, M.A. Greenstone. (CERS Journals Ltd 1995.

ABSTRACT: A 51 year old man with mild rheumatoid arthritis developed pulmonary hypertension in the absence of interstitial lung disease. A cutaneous vasculitis subsequently responded to immunosuppressive therapy, but the lung disease was refractory to treatment.

In patients with rheumatoid arthritis, dyspnoea should be investigated at an early stage, even in the absence of obvious pleural or interstitial lung disease.

Eur Respir J., 1995, 8, 331-333.
*Medical Chest Unit, Castle Hill Hospital, Cottingham, North Humberside, UK. **Dept of Pathology, Killingbeck Hospital, Leeds, UK.

Correspondence: M.A. Greenstone, Medical Chest Unit, Castle Hill Hospital, Cottingham, Hull, HU16 5JQ, UK

Keywords: Pulmonary hypertension vasculitis

Received: February 91994

Accepted after revision August 231994
Lung involvement in rheumatoid arthritis is common and usually presents with pleural disease or diffuse interstitial fibrosis $[1,2]$. Involvement of the small airways is a well-described but unusual manifestation, and involvement of the pulmonary vasculature an extremely rare, and usually coincidental, finding at autopsy [3, 4]. We report a patient with both of these unusual manifestations of rheumatoid lung, in whom severe pulmonary hypertension developed in the absence of interstitial lung disease. In this case, clinically significant pulmonary vascular disease preceded vasculitis elsewhere, and occurred against a background of mild articular disease.

\section{Case report}

A 51 year old nonsmoker with a history of mild asthma presented with an 8 month history of deteriorating exercise tolerance. He was no longer able to cycle more than a few hundred metres, was dyspnoeic on climbing stairs, and had been forced to give up his job as a postman. Rheumatoid arthritis, affecting principally the right knee, had been diagnosed on the basis of a synovial biopsy and a positive rheumatoid factor 15 yrs previously. He took paracetamol occasionally for the knee pain, but was on no medication apart from inhaled salbutamol and beclomethasone.

Examination revealed central cyanosis, no clubbing, and a few crackles at both lung bases. There was a parasternal heave but normal heart sounds, no increase in venous pressure and blood pressure was 140/86 $\mathrm{mmHg}$. There was minimal evidence of rheumatoid arthritis, apart from slight restriction of movement in the right knee. Serial chest X-rays showed an increase in the size of the cardiac silhouette and pulmonary arteries over a 5 year period, but no evidence of interstitial lung disease.
Electrocardiography (ECG) showed evidence of pulmonary hypertension with "P" pulmonale and evidence of right ventricular hypertrophy. ECG showed reasonable left ventricular function but paradoxical septal movement. The right atrium and ventricle were markedly dilated, but there was little sign of ventricular hypertrophy and no intracardiac shunt. Doppler measurements of the right ventricular systolic pressure were not performed. Perfusion lung scanning showed no evidence of thromboembolic disease. Computerized tomographic scanning of the thorax was normal with no evidence of emphysema, pleural, or interstitial lung disease.

Lung function tests showed mild airflow obstruction with forced expiratory volume in one second $\left(\mathrm{FEV}_{1}\right)$ $2.9 \mathrm{l} \cdot \mathrm{s}^{-1}$ (81\% predicted), forced vital capacity (FVC) 4.6 $l\left(98 \%\right.$ pred), and $\mathrm{FEV}_{1} / \mathrm{FVC}$ ratio $66 \%$. There was evidence of hyperinflation and gas-trapping, with a total lung capacity (TLC) $120 \%$ pred, and residual volume (RV) $154 \%$ pred. Corrected gas transfer coefficient (KCO) was grossly impaired at $13 \%$ pred. A flow-volume loop suggested small airways disease, with forced mid-expiratory flow (FEF25-75) only $28 \%$ pred. Arterial blood gases breathing room air showed $\mathrm{pH} 7.45$, arterial oxygen tension $\left(\mathrm{PaO}_{2}\right) 8.4 \mathrm{kPa}$, arterial carbon dioxide tension $\left(\mathrm{PaCO}_{2}\right) 3.2 \mathrm{kPa}$, and base excess $4.2 \mathrm{mmol} \cdot l^{-1}$. Sleep studies excluded any form of sleep-disordered breathing. Rheumatoid factor was positive in a titre of 1:640. Full blood count was normal with an erythrocyte sedimentation rate of $20 \mathrm{~mm}$ in the first hour.

Open lung biopsy showed severe pulmonary vascular disease. All the small arteries showed severe medial hypertrophy, and many of them demonstrated advanced fibroelastic intimal proliferation to the point of luminal occlusion. Elsewhere, the intimal proliferation was of a mixed pattern with eccentric foci. Uniformly concentric ("onion skin" like) proliferation, suggestive of primary 
pulmonary hypertension, was not seen. These changes were marked in elastic and muscular arteries, and confirmed severe pulmonary hypertension. In addition, there was marked focal destruction of both internal and external elastic laminae of the walls of the arteries, which in some instances was associated with patchy destruction of the media, which was replaced by fibroblastic granulation tissue. This mural destruction and replacement by granulation tissue was irregular and diffuse, and hence could be distinguished from typical circumscribed plexiform lesions. No plexiform lesions were seen (fig. 1). In the absence of active vasculitis, primary pulmonary hypertension could not be absolutely excluded, although the changes were considered to be typical of a healing vasculitis. In addition, there was widespread hyperplasia of bronchus-associated lymphoid tissue, with lymphoid aggregates and germinal follicles related to terminal and respiratory bronchioles. These focal changes were typical of follicular bronchiolitis. There was no evidence of obliterative bronchiolitis or fibrosing alveolitis (fig. 2).

A trial of prednisolone made no difference to the patient's breathlessness and may have precipitated an episode of fluid retention. Steroids were withdrawn and the oedema resolved with diuretics. Some months later, the patient developed a vasculitic rash on both legs which responded to prednisolone and azathioprine. Exercise tolerance continued to decline despite home oxygen, and he died suddenly at home 18 months after presentation. No postmortem was held.

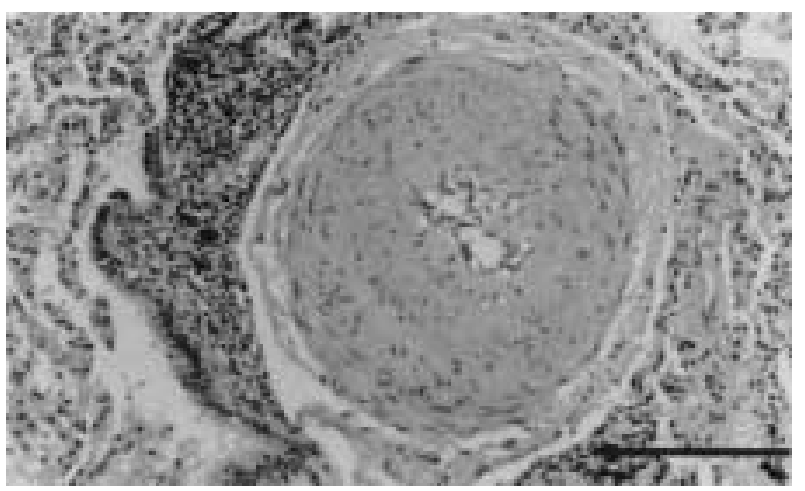

Fig. 1. - Pulmonary hypertension. Pulmonary artery showing extensive medial muscular hypertrophy. (Haematoxylin and eosin; magnification $\times 40$; scale bar $\left.=0.5 \times 10^{-3} \mathrm{~m}\right)$.

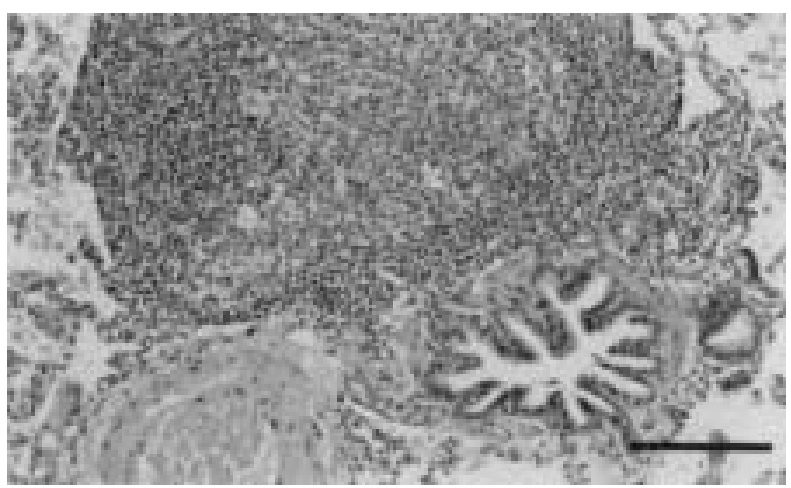

Fig. 2. - Follicular bronchiolitis. Prominent lymphoid aggregates with germinal centres are seen in peribronchial locations. (Haematoxylin and eosin; magnification $\times 25$; scale bar $=0.5 \times 10^{-3} \mathrm{~m}$ ).

\section{Discussion}

Pulmonary hypertension is quite common in patients with systemic sclerosis, but rare in rheumatoid arthritis [1]. In this latter group, the disease is usually secondary to interstitial fibrosis or due to associated primary pulmonary hypertension. Very few cases of pulmonary hypertension have been documented as secondary to histologically proven pulmonary vasculitis [5-7], and the distinction between vasculitis and changes secondary to pulmonary hypertension of any cause can be problematic [8]. In the case reported here, rheumatoid arthritis was confirmed by a positive rheumatoid factor and synovial biopsy, although the rheumatoid disease was mild as judged by current articular involvement. Even though there was no suggestion of a systemic vasculitis prior to his presentation with breathlessness, the patient eventually developed classical cutaneous vasculitis.

We considered the possibility that this man suffered from primary pulmonary hypertension, but the age and sex of the patient were unusual, as were the pattern of vessel damage and the absence of plexogenic arteriopathy. The very abnormal gas transfer coefficient is much lower than is normally seen in patients with primary pulmonary hypertension, and is more compatible with the proven vasculitis $[9,10]$. The fact that the patient subsequently developed evidence of a cutaneous vasculitis supports the hypothesis that the pulmonary hypertension was secondary to rheumatoid vasculitis.

Lung function testing suggested airflow obstruction in the small airways [11]. The common form of small airways disease in rheumatoid arthritis is progressive obliterative bronchiolitis, and is usually manifested by severe reduction in the $\mathrm{FEV}_{1} / \mathrm{FVC}$ ratio. Follicular bronchiolitis is a very rare form of small airways disease occurring in rheumatoid arthritis, clinically similar to obliterative bronchiolitis, and only diagnosed by typical histological changes [12]. The finding of a form of bronchiolitis, which is also known to be closely associated with rheumatoid arthritis, is further evidence that the patient's lung disease was due to rheumatoid arthritis.

Pulmonary vascular disease and small airway obstruction should be considered in the differential diagnosis of the breathless patient with rheumatoid arthritis. The rheumatoid disease may be mild, as judged by articular involvement, and clinicians should not dismiss complaints of breathlessness in patients with rheumatoid arthritis but no evidence of pleural or interstitial lung disease. It is possible that earlier diagnosis and immunosuppressive treatment of the vasculitis might have delayed, or even prevented, the fatal outcome, but by the time the diagnosis was made the pulmonary vasculitis was wellestablished, and pulmonary hypertension had already developed.

In patients with primary pulmonary hypertension, it is thought that diagnosis in the early stages of the disease when the pathological changes have not yet become irreversible, results in a better prognosis [13]. Treatment with anticoagulants and vasodilators results both in symptomatic and objective improvement in some patients, and may delay the necessity for transplantation [14]. 
Whether this applies to other forms of nonembolic pulmonary vascular disease is unknown, but seems a logical assumption on which to base treatment decisions. The development of pulmonary vasculitis in rheumatoid arthritis is too unusual to recommend routine surveillance in all patients with rheumatoid disease, but it is suggested that early physiological investigation of dyspnoeic symptoms might indicate which patients need screening for pulmonary hypertension.

Acknowledgements: The authors thank P. Bury for the initial histological review, and A. Ellis and A. Gibbons for secretarial assistance.

\section{References}

1. Hunninghake GW, Fauci AS. Pulmonary involvement in the collagen vascular diseases. Am Rev Respir Dis 1979; 119: 471-503.

2. Kelly CA. In: Kelly CA, ed. Lung Disease in Rheumatic Disorders. Clin Rheum. London, Balliere Tindall 1993; pp. 1-29.

3. Yousem SA, Colby CV, Carrington CB. Lung biopsy in rheumatoid arthritis. Am Rev Respir Dis 1985; 131: 770-777.

4. Asherson RA, Morgan SH, Hackett D, et al. Rheumatoid arthritis and pulmonary hypertension. A report of three cases. J Rheumatol 1985; 12: 154-159.
5. Morikawa J, Kitamura K, Habuchi Y, et al. Pulmonary hypertension in a patient with rheumatoid arthritis. Chest 1988; 93: 876-878.

6. Young ID, Ford SE, Ford PM. The association of pulmonary hypertension with rheumatoid arthritis. $J$ Rheumatol 1989; 169: 1266-1269.

7. Baydur A, Mongan ES, Slager UT. Acute respiratory failure and pulmonary arteritis without parenchymal involvement. Chest 1979; 75: 518-520.

8. Kay JM, Banik S. Unexplained pulmonary hypertension with pulmonary arteritis in rheumatoid disease. $\mathrm{Br}$ J Dis Chest 1977; 71: 53-59.

9. Burke CM, Glanville AR, Morris AJ. Pulmonary function in advanced pulmonary hypertension. Thorax 1987; 42: 131-135.

10. Williams WH, Adler JJ, Colp C. Pulmonary function studies as an aid in the differential diagnosis of pulmonary hypertension. Am J Med 1969; 47: 378-383.

11. Geddes DM, Corrin B, Brewerton DA, et al. Progressive airway obliteration in adults and its association with rheumatoid disease. Q J Med 1977; 184: 427-444.

12. Yousem SA, Colby CV, Carrington CB. Follicular bronchitis/ bronchiolitis. Hum Pathol 1985; 16: 700706.

13. Rozkovec P, Montanes P, Oakley CM. Factors that influence the outcome of primary pulmonary hypertension. Br Heart J 1986; 55: 449-458.

14. Dinh Xuan AT, Higenbottam TW, Scott JP, Wallwork J. Primary pulmonary hypertension: diagnosis, medical and surgical treatment. Respir Med 1990; 84: 189-197. 